\title{
The role of reoperative thoracoabdominal surgery in the current era
}

\author{
Ehud Raanani, MD
}

\footnotetext{
From the Department of Cardiac Surgery, and Leviev Cardiothoracic and Vascular Center, Sheba Medical Center, Ramat Gan; and the Department of Surgery, Tel Aviv University, Tel Aviv, Israel. Disclosures: Author has nothing to disclose with regard to commercial support.

Received for publication Sept 22, 2017; accepted for publication Sept 27, 2017; available ahead of print Nov 3, 2017.

Address for reprints: Ehud Raanani, MD, Director of Cardiac Surgery Department, Sheba Medical, Emek HaEla St 1, Ramat Gan, Israel (E-mail: ehud.raanani@sheba.health.gov.il).

J Thorac Cardiovasc Surg 2018;155:486-7

$0022-5223 / \$ 36.00$

Copyright $(2) 2017$ by The American Association for Thoracic Surgery

https://doi.org/10.1016/j.jtcvs.2017.09.119
}

Since the introduction of endovascular repair for aortic aneurysms, and more recently also for complex thoracoabdominal aortic aneurysms (TAAAs), many centers have reduced the number of open surgical interventions, including redo TAAA interventions, in favor of the endovascular approach. Such measures are usually justified because of the known high risk of morbidity and mortality in patients with such aneurysms.

This approach toward more endovascular intervention must be weighed against the suboptimal clinical outcomes that occur in some groups of patients, however, such as young patients with connective tissue diseases (Marfan syndrome). ${ }^{1}$ These patients demonstrate a higher risk for early or late endoleak, and because of young age, they require the best and longer lasting solutions.

In this issue of the Journal, Coselli and colleagues ${ }^{2}$ from the Baylor College of Medicine in Texas present their early and late surgical results in the largest series of patients in the literature to undergo reoperative surgery for TAAA. ${ }^{2}$ These patients are usually considered to be at extreme risk, not only because of their basic complex pathology but also because of the risk of increased postoperative bleeding and other complications during reentry of the thoracic and abdominal cavities. Additional concern is warranted because of the possibility of elevated rates of paraplegia after TAAA repair in patients with previous open thoracic or abdominal aortic aneurysm repair.

This study compared the clinical outcomes of 2 patient groups: those who underwent reoperative TAAA repair and a consecutive group who underwent first-time TAAA open surgery. The most striking finding in this study was the fact that the operative mortality did not differ between the groups $(8.1 \%$ for reoperative vs $7.3 \%$ for nonreoperative) and the reoperative repair was not associated with an increased risk of surgical morbidity. These formidable results are first and foremost attributable to the excellent surgical capability of this surgical team and their immense experience in treating this type of pathology. treatment.

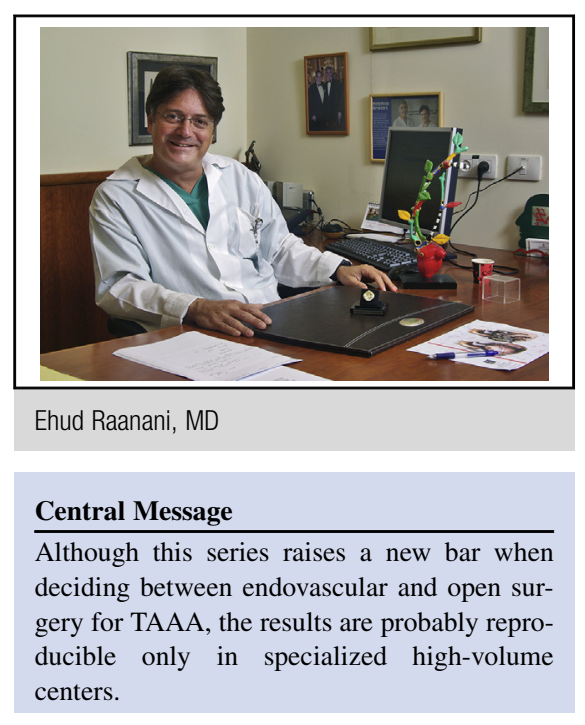

See Article page 474

There may, however, be other reasons explaining these good results. First, the reoperative group was probably a selected group of strong patients simply because they had successfully survived the first operation. Second, there may have been a selection bias by accepting for surgery the "better" and generally more robust patients. In addition, there is some clinical evidence that suggests that staging open distal aortic surgery contributes to the development of a collateral network to the spinal cord and may reduce the total risk of paraplegia.

The disappointing finding in this excellent study of Coselli and colleagues ${ }^{2}$ is that of low 10-year survival estimates of $23.9 \% \pm 4.9 \%$ for patients with repair failure and $28.4 \% \pm 2.0 \%$ for those with extension of repair, both of which survivals were unrelated to the age of the patient at the time of surgery. This reduced midterm to long-term survival could be used as a case in favor of the endovascular approach, because for reduced life expectancy, one could argue that a less invasive approach may be sufficient, even at the price of somewhat less effective

Finally, although Coselli and colleagues ${ }^{2}$ have raised a high bar of surgical success which should be used when comparing between other endovascular alternatives, unfortunately these results are probably reproducible only in selected expert, high-volume TAAA centers. 


\section{References}

1. Preventza O, Mohammed S, Cheong BY, Gonzalez L, Ouzounian M, Livesay JJ, et al. Endovascular therapy in patients with genetically triggered thoracic aortic disease: applications and short- and mid-term outcomes. Eur J Cardiothorac Surg. 2014;46:248-53.
2. Coselli JS, Rosu C, Amarasekara HS, Green SY, Zhang Q, Price MD, et al. Reoperative surgery on the thoracoabdominal aorta. J Thorac Cardiovasc Surg. 2018; 155:474-85.

3. Etz CD, Zoli S, Mueller CS, Bodian CA, Di Luozzo G, Lazala R, et al. Staged repair significantly reduces paraplegia rate after extensive thoracoabdominal aortic aneurysm repair. J Thorac Cardiovasc Surg. 2010;139:1464-72. 